\title{
An early look at where the federal parties stand on health care
}

Cite as: CMAJ 2019 July 22;191:E826-7. doi: 10.1503/cmaj.109-5793

Posted on cmajnews.com on July 4, 2019.

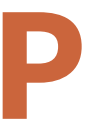

harmacare and climate change are shaping up to be key issues in this year's federal election. However, with more than three months until Canadians head to the polls, only the New Democrats have released the bulk of their platform.

Climate change and health care top the list of Canadians' concerns, after cost of living, according to a recent poll commissioned by $C B C$ News. This may provide an opening for the NDP and Green Party, and potentially split left-leaning voters, in what is predicted to be a close race between the sitting Liberal government and Conservatives.

NDP Leader Jagmeet Singh is promising a major expansion of medicare, starting with the rollout of a national, universal public pharmacare program by 2020. An NDP government would invest $\$ 10$ billion annually to support the program, and work towards universal coverage of dental, mental, fertility, vision and hearing care.

The NDP would enforce the Canada Health Act to stop privatization of health services and user fees, make a plan to recruit and retain doctors, nurses and other health professionals, prevent the sale of blood products, and ensure equal access to abortion.

The party is also committing to develop national strategies for seniors, austism and suicide, declare the opioid epidemic a public health emergency and seek compensation from drug companies for their role in the crisis, and make investments in health care infrastructure in Indigenous communities.

So far, these are the only substantive health care promises from any major party. Prime Minister Justin Trudeau says the Liberals are committed to a national pharmacare program, but the party has not released details. As a first step, the 2019 budget earmarked $\$ 35$ million over four years to create a national drug agency to make a list of medications that should be covered and negotiate lower prices. A federal advisory panel has since called for a \$15-billion universal public pharmacare program.

Conservative Leader Andrew Scheer, meanwhile, dismissed the panel's recommendations. He argued that there are other ways for the federal government to ensure Canadians have access to necessary drugs, such as filling gaps in coverage for people without access to provincial or employer-sponsored plans.

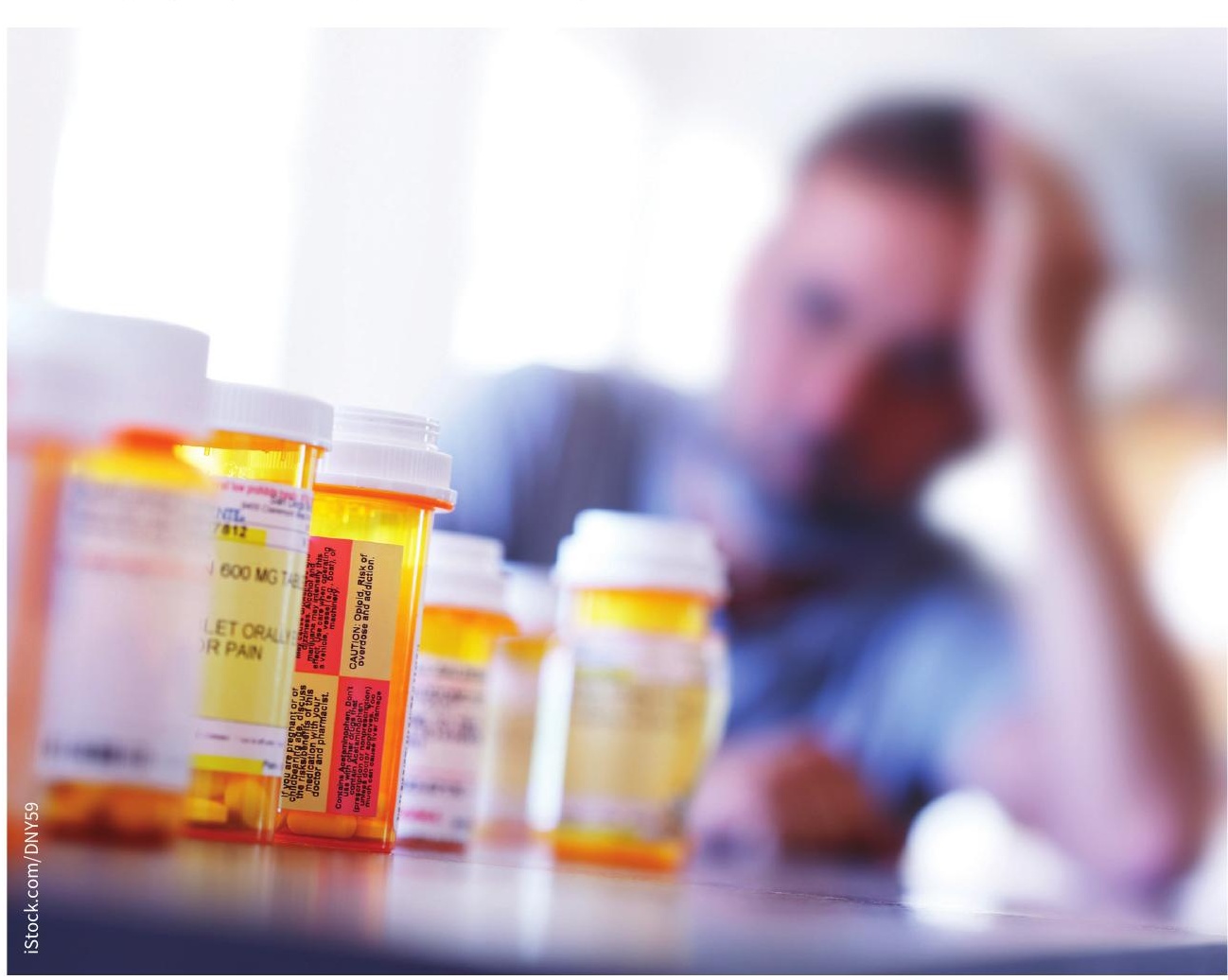

Pharmacare will be a key issue as federal parties gear up for the 2019 election.
Scheer has endorsed a more handsoff approach to health care, saying he would foster a decentralized federation in which decisions would be made by the smallest governments closest to the people affected. A Conservative federal government would provide predictable health funding to provinces to use how they see fit.

The threat posed by climate change and its importance to voters, however, appears to be mobilizing all parties. The issue ranks second among Canadians' concerns heading into the election, according to the CBC News poll, and health organizations are urging action to prevent harms to human health. 
The Green Party has the most comprehensive plan to tackle climate change. They're promising to double Canada's emission reductions target to $60 \%$ by 2030 to reach zero emissions by 2050 . The party would also declare a climate emergency, ban fracking, make a nationwide shift to non-nuclear renewable energy, and retrofit all buildings to be carbon neutral by 2030.

The NDP has committed to similar measures, promising to spend \$15 billion in its first four years in power to fight cli- mate change by investing in areas such as public transit and subsidizing zeroemission vehicles built in Canada. The NDP is also promising to power Canada with net carbon-free electricity by 2030 , ban single-use plastics, and retrofit all housing in the country to be energyefficient by 2050 . The Liberals and Conservatives have also released climate plans, although with less ambitious targets. The Liberals' plan includes investing in renewables to get to $90 \%$ clean energy, putting a price on pollution, phasing out coal, supporting more than 1000 public transit projects and investing in energyefficient buildings.

The Conservatives' approach would be to incentivize private-sector research and development of green technology. They've committed to set emissions standards for major polluters, issue more bonds to finance emission-reducing technologies, and create a tax credit for energy-saving home renovations.

Lauren Vogel, CMAJ 